\title{
Engulfment of platelets delays endothelial cell aging via girdin and its phosphorylation
}

\author{
YONG LAN ${ }^{1}$, YONGJUN LI ${ }^{1}$, DAJUN LI ${ }^{1}$, PENG LI $^{1}$, JIYANG WANG ${ }^{1}$, \\ YONGPENG DIAO ${ }^{1}$, GUODONG $\mathrm{YE}^{1}$ and YANGFANG $\mathrm{LI}^{2}$ \\ ${ }^{1}$ National Center of Gerontology, Department of Vascular Surgery, Beijing Hospital, Beijing 100730; \\ ${ }^{2}$ Beijing Neurosurgical Institute, Capital Medical University, Beijing 100050, P.R. China
}

Received November 7, 2017; Accepted May 10, 2018

DOI: $10.3892 /$ ijmm.2018.3685

\begin{abstract}
Endothelial cells are critical in angiogenesis and maintain the homeostasis of the blood-brain barrier (BBB). Platelets (PLTs) are essential in vascular biology, including angiogenesis. The present study aimed to investigate the effect of PLTs on the aging of endothelial cells. Human brain microvascular endothelial cells (HBMECs) and human astrocytes were co-cultured to mimic the BBB. Transmission electron microscopy was used to observe the engulfment of PLTs. Confocal microscopy was used to observe the co-localization of PLTs, girders of actin filament (girdin) and phosphorylated (p-)girdin. Senescence-associated $\beta$-galactosidase $(\beta$-gal) staining, 3-(4,5-dimethylthiazol-2-yl)-2,5-diphenyltetrazolium bromide and flow cytometry were performed to examine the cell senescence, viability and apoptosis, respectively. Transwell assays were performed to examine cell invasion and migration. Western blot analysis was performed to detect the expression of girdin, AKT and p-AKT. PLTs delayed senescence, and promoted the viability and resistance to apoptosis of the HBMECs. Cell invasion and migration were enhanced by PLTs. In addition, girdin and p-girdin were essential to the engulfment of HBMECs to PLTs. Mechanically, the inhibition of AKT signals reversed the effect of PLTs on HBMECs by increasing the activity of $\beta$-gal, decreasing the cell viability, and inhibiting the invasion and migration of the HBMECs. The engulfment of PLTs assisted in delaying the aging of endothelial cells via girdin and p-girdin, in which the AKT signal was involved. The present study indicated a potential strategy for delaying endothelial cell aging in the treatment of central nervous system diseases.
\end{abstract}

Correspondence to: Dr Yangfang Li, Beijing Neurosurgical Institute, Capital Medical University, 6 Tiantan Xili, Dongcheng, Beijing 100050, P.R. China

E-mail: cclslyf@163.com

Key words: platelets, endothelial cells aging, girdin, protein kinase B, blood-brain barrier

\section{Introduction}

The blood-brain barrier (BBB), as a membrane barrier in the central nervous system (CNS) that separates the brain from circulating blood, is vital to maintain neural microenvironment homeostasis and low permeability, which is closely associated with CNS disease (1). Endothelial cells are not only the primary components of the $\mathrm{BBB}$, but they are also important in the BBB. Angiogenesis is critical in the formation of new blood vessels within this brain microvessel network (2). The initiation of angiogenesis and the formation of early vascular structures depend on endothelial cells (3), which are essential for maintaining the function and regulating the proliferation of vessels. Endothelial cells are also important in damage repair, ischemic adaptation and tumor formation $(4,5)$. However, changes in the function and structure of the vascular wall occur with increasing age or through stimuli from other environmental factors, including hypertension, smoking and drinking. This leads to the compromised ability of endothelial cells in proliferation, migration and damage repair $(6,7)$, which results in disrupted vascular hemostasis and vessel aging.

It is accepted that the dynamic reorganization of the actin cytoskeleton is important in cellular morphogenesis and motility. The phosphatidylinositol 3-kinase (PI3K)-AKT pathway exerts functions downstream of growth factors in facilitating endothelial cell growth, and its downstream targets are involved in vascular remodeling (8-10). Girders of actin filament (girdin), as an actin-binding protein in mammalian tissues, is expressed in limited cell types, including immature endothelial cells, which can be phosphorylated by AKT at serine $1417(11,12)$. It has been reported that girdin is important in cell migration, which relies on extracellular signals and the surrounding microenvironment. Therefore, it is of value to delay the aging of endothelial cells and modulate the relevant molecule signaling for the prevention of CNS disease.

Platelets (PLTs), as fragments of cytoplasm derived from megakaryocytes, are components of the blood in mammals (13). The importance of PTLs in the inflammatory response has been reported. In addition, extensive evidence has revealed that PLTs are essential in vascular biology, including angiogenesis and tissue regeneration $(14,15)$. Through various angiogenic stimulators, PLTs are capable of promoting de novo vessel growth. In the presence of vascular 
endothelial growth factor and platelet-derived growth factor, the proliferation of endothelial cells can be induced and their migration can be increased (16-18). Previously, attributable to concentrated biologically active molecules, platelet-rich plasma (PRP), as PLTs concentrate, has become more common as a clinical treatment to induce healing and regeneration, and control inflammation (19-21). Furthermore, exosome derived from PLTs has attracted wide attention owing to its role in angiogenesis and neovascularization $(22,23)$. PLTs can be engulfed by endothelial cells (24), however, the precise effect of internalized PLTs on endothelial cells remains to be elucidated.

Multiple BBB in vitro models have been established, including monoculture, co-culture and triple culture systems. These systems have their respective advantages and disadvantages (25-27). In the present study, human brain microvascular endothelial cells (HBMECs) were used to mimic the BBB owing to its brain origin. Therefore, this model offers a more representative $\mathrm{BBB}$ model compared to several other cell lines currently used (26). In the present study, the effects of internalized PLTs on HBMEC senescence, proliferation, apoptosis, invasion and migration were determined, and the associated mechanisms were established in vitro. This information may provide a novel method for delaying the aging of endothelial cells, inspiring a potential strategy for angiogenesis in the treatment of CNS diseases.

\section{Materials and methods}

Cell culture and treatment. The HBMECs (ScienCell Research Laboratories, Carlsbad, CA, USA) were cultured with endothelial cell medium (ScienCell Research Laboratories) containing 10\% fetal bovine serum (FBS) and $1 \%$ endothelial cell growth supplement (ScienCell Research Laboratories) in a $5 \% \mathrm{CO}_{2}$ humidified incubator at $37^{\circ} \mathrm{C}$. The HBMECs $\left(5 \times 10^{4}\right.$ cells per $\left.\mathrm{cm}^{2}\right)$ were seeded on a collagen/fibronectin-coated Transwell insert. Subsequently, human astrocytes (HAs) (ScienCell Research Laboratories) were seeded $\left(5 \times 10^{4}\right.$ cells per $\left.\mathrm{cm}^{2}\right)$ onto the carrier plates in the Transwell and cultured with astrocyte medium (ScienCell Research Laboratories). The medium was replaced with fresh medium every other day. After 3 days, the insert coated with HBMECs was added to dishes containing the HAs. Lipofectamine 3000 (cat. no. L3000008; Invitrogen; Thermo Fisher Scientific, Inc., Waltham, MA, USA) was used for cell transfection. Short hairpin (sh)-girdin plasmid (cat. no. sc-94984-SH) and control shRNA plasmid (cat. no. sc-108060) were purchased from Santa Cruz Biotechnology, Inc. (Dallas, TX, USA). Mutated girdin was mutated at Ser-1417 to Ala, which was resistant to phosphorylation, using a site-directed mutagenesis kit (Tiangen Biotech Co., Ltd., Beijing, China). Treatment with triciribine (Merck Millipore, Darmstadt, Germany) at $20 \mu \mathrm{M}$ for $48 \mathrm{~h}$ was performed to inhibit AKT signals (28).

Isolation and labeling of PLTs. Healthy volunteers (8 men and 8 women) with an average age of $30.2 \pm 12.6$ years, were recruited at Beijing Hospital (Beijing, China) in August 2014, with the approval of the Ethics Committee of Beijing Hospital. Informed consent was obtained from the volunteers. The PLTs were isolated from the whole blood of volunteers using a platelet preparation kit (cat. no. CS0257; Leagene Biotech Co., Ltd., Beijing, China). Briefly, $30 \mathrm{ml}$ venous blood was collected and mixed with anticoagulant. The blood was then transferred to a centrifuge for $15 \mathrm{~min}$ at $2,000 \times \mathrm{g}$ at $4^{\circ} \mathrm{C}$. The upper supernatant was carefully collected and the centrifugation was repeated to acquire the PLTs. The PLTs were washed with 100 nM PGE-1 (Sigma-Aldrich; Merck Millipore) and $1.9 \mathrm{mM}$ theophylline. The PLTs were labeled with PKH-26 according to the manufacturer's protocol (Mini 26; Sigma; Merck Millipore). According to a previous study (29), the PLTs were added to the medium at an HBMEC:PL ratio of $1: 40$, and were incubated for $20 \mathrm{~h}$ at $37^{\circ} \mathrm{C}$.

$\beta$-galactosidase ( $\beta$-gal) staining. The activity of senescence-associated (SA)- $\beta$-gal was detected with a $\beta$-gal staining kit (cat. no. C0602; Beyotime Institute of Biotechnology, Haimen, China). Briefly, the cells were fixed in $0.2 \%$ glutaraldehyde solutions for $5 \mathrm{~min}$, following which the cells were stained with $\mathrm{X}$-gal solution for $18 \mathrm{~h}$ at $37^{\circ} \mathrm{C}$. The SA- $\beta$-gal-positive cells were observed under a phase-contrast microscope at x100 or x400 magnification (Olympus, Tokyo, Japan). The proportions of cells positive for SA- $\beta$-gal activity were determined as a percentage of the total number of cells counted in each dish.

\section{3-(4,5-dimethylthiazol-2-yl)-2,5-diphenyltetrazolium} bromide (MTT) assay. An MTT kit (Beyotime Institute of Biotechnology) was used to detect cell viability. The cells $\left(2 \times 10^{3}\right.$ cells per well) were seeded into a 96 -well plate (Corning Costar, Cambridge, MA, USA). After 24 h, the cells were treated with PLTs alone or with PLTs plus cytochalasin D $\left(1 \mu \mathrm{g} / \mathrm{ml}\right.$,) for $14 \mathrm{~h}$ at $37^{\circ} \mathrm{C}$, following which $100 \mu \mathrm{g}$ MTT was added to the wells. The incubation with cytochalasin D was 30 min only. The medium was removed following incubation for $4 \mathrm{~h}$. Subsequently, $150 \mu \mathrm{l}$ dimethyl sulfoxide (DMSO) was added to dissolve the purple formazan formed by the reduction of MTT. The absorbance at a $490 \mathrm{~nm}$ was measured with a microplate reader.

Flow cytometry for detection of the engulfment of PLTs. The engulfment of fluorescent PKH26-labeled PLTs by endothelial cells was determined using flow cytometry. Briefly, the cells were incubated in HEPES-buffer, comprising $134 \mathrm{mM} \mathrm{NaCl}$, $6 \mathrm{mM} \mathrm{KCl}, 2 \mathrm{mM} \mathrm{CaCl}_{2}, 1 \mathrm{mM} \mathrm{MgCl}, 10 \mathrm{mM}$ HEPES and $10 \mathrm{mM}$ glucose ( $\mathrm{pH} \mathrm{7.40)}$, and anti-PLT antibody (AIP21; cat. no. ab112238; Abcam, Cambridge, MA, USA; $100 \mathrm{nM}$ ) for $30 \mathrm{~min}$ at $4^{\circ} \mathrm{C}$, followed by a 15 -min wash with $1 \mathrm{X}$ PBS buffer. Flow cytometric analysis (BD FACSCalibur; BD Biosciences, Franklin Lakes, NJ, USA) was used to analyze the mean fluorescence intensity.

Flow cytometric analysis of apoptosis. Apoptosis was determined using an Annexin V/PI apoptosis kit (MultiSciences Biotech Co., Ltd., Hangzhou, China). The cells were harvested and centrifuged at $2,000 \mathrm{x}$ g at $4^{\circ} \mathrm{C}$ for $5 \mathrm{~min}$. Following collection, the cells were resuspended in $0.5 \mathrm{ml} 1 \mathrm{X}$ annexin-binding buffer at a density of $5 \times 10^{5}$ cells $/ \mathrm{ml}$. Annexin V-FITC and PI were added and the cells were incubated for $10 \mathrm{~min}$ at room 
A

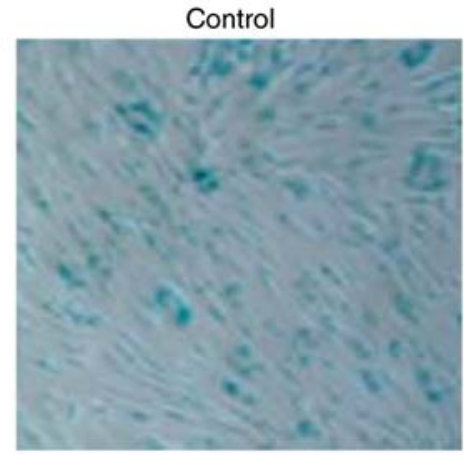

PLT

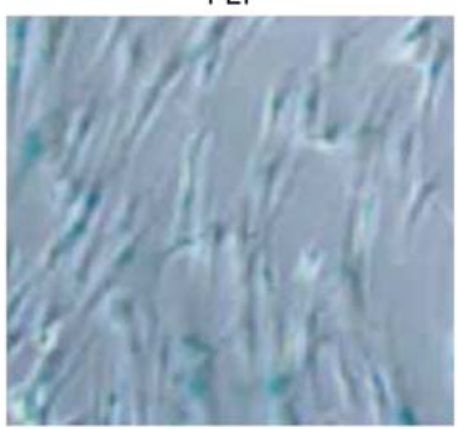

PLT+Cytochalasin

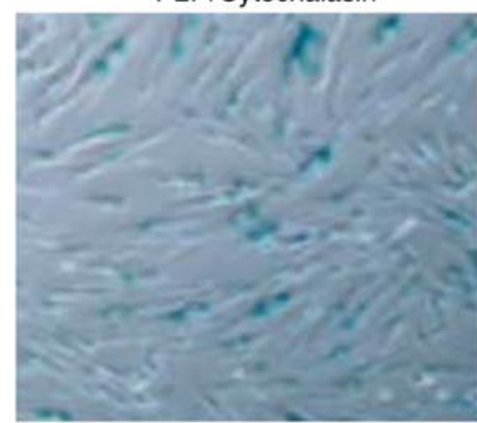

B

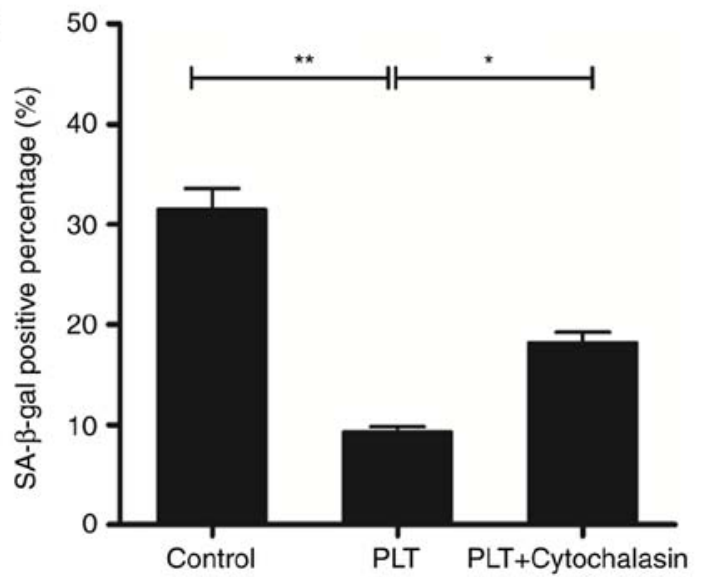

C

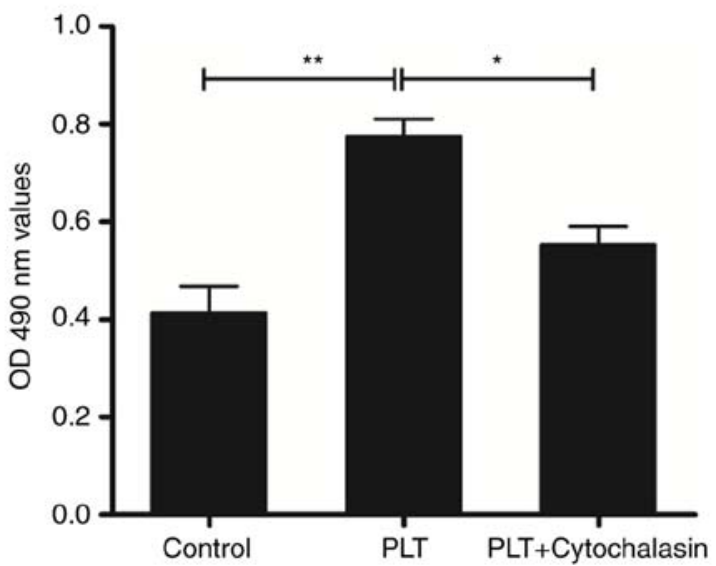

Figure 1. Phagocytosis of PLTs mitigates cell aging. (A) Cell senescence was determined by SA- $\beta$-gal staining (magnification, $x 100)$ and (B) quantified. (C) Cell viability was evaluated using a 3-(4,5-dimethylthiazol-2-yl)-2,5-diphenyltetrazolium bromide assay. "P<0.05 and ${ }^{* *} \mathrm{P}<0.01$. PLT, platelet; SA- $\beta$-gal, senescence-associated $\beta$-galactosidase.

temperature in the dark. The samples were immediately analyzed by flow cytometry.

Transmission electron microscopic observation. In brief, the cells were fixed in $4 \%$ glutaraldehyde/ $1 \%$ paraformaldehyde for $2 \mathrm{~h}$ at room temperature, and then post-fixed in $1 \% \mathrm{OsO}_{4}$ for $1 \mathrm{~h}$ at $4^{\circ} \mathrm{C}$. Following dehydration in graded ethanol (70, 95 and 100\%), the cells were embedded in LX112. Ultrathin sections $(50 \mathrm{~nm})$ were stained with $1 \%$ uranyl acetate and lead citrate, and were then examined for mitochondrial morphology on a $\mathrm{H} 7000$ electron microscope operating at 80 kV (Hitachi, Ltd., Tokyo, Japan).

Confocal microscopy. The cell sections were incubated with $3 \%$ hydrogen peroxide for $10 \mathrm{~min}$. Normal goat serum (Beijing Solarbio Science \& Technology Co., Ltd., Beijing, China) was added to the sections and incubated at room temperature for $2 \mathrm{~h}$. Subsequently, the sections were incubated with anti-PLT antibody (100 nM; cat. no. ab53304; Abcam), anti-girdin antibody (1:500; cat. no. ab179481; Abcam), or anti-girdin (phosphorylated $\mathrm{S} 1417)$ antibody $(8 \mu \mathrm{g} / \mathrm{ml}$; cat. no. 28067; Takara Bio, Inc., Otsu, Japan) at $4^{\circ} \mathrm{C}$ overnight. The secondary antibodies, FITC-donkey anti-rabbit IgG (1:200; JacksonImmuno Research Laboratories, Inc., West Grove, PA, USA) and anti-rabbit IgG (H+L) F(ab')2 Fragment (1:500; Alexa Fluor ${ }^{\circledR} 488$ Conjugate; cat. no. 4412; Cell Signaling Technology, Inc., Danvers, MA, USA) were added and incubated at $4^{\circ} \mathrm{C}$ overnight. Finally, the sections were mounted with FlourSave (Calbiochem; Merck Millipore) mounting reagent. Images of the histological sections were captured using Northern Eclipse software version 6.0 (Empix Imaging, Inc., Mississauga, ON, Canada) on a Zeiss Axioplan 2 imaging microscope (Carl Zeiss, Toronto, ON, Canada).

Transwell assay. A precoated cell invasion kit (pore size 8.0- $\mu \mathrm{m}$; Corning Costar) and Matrigel (250 $\mu \mathrm{g} / \mathrm{ml}$; BD Biosciences) in Transwell chambers were used in Transwell assays. The cells were plated at a density of $5 \times 10^{4} / \mathrm{ml}$ in the upper chambers without FBS. The cells migrated to the lower chamber containing medium with $30 \%$ FBS. The invaded cells were fixed with paraformaldehyde after $60 \mathrm{~h}$ incubation and stained with $0.1 \%$ crystal violet. The numbers of cells that invaded through the membrane were counted under a light microscope (Nikon Ni-E; Nikon Corporation, Tokyo, Japan) in four randomly selected fields per well.

Western blot analysis. The samples were incubated with an NP40 lysis buffer (Beijing Solarbio Science \& Technology Co., Ltd.) with protease inhibitors (Promega Corporation, Madison, WI, USA). Then the concentration of the protein samples was estimated using a bicinchoninic acid protein quantitation kit (Thermo Fisher Scientific, Inc.). Protein extract (35 $\mu \mathrm{g}$ per group) was separated on $8 \%$ SDS-polyacrylamide gels and transferred onto a nitrocellulose membrane. The membrane was blocked in $5 \%$ skim milk powder solution 
A

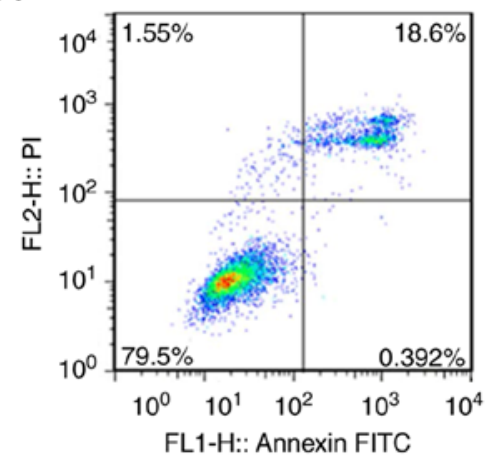

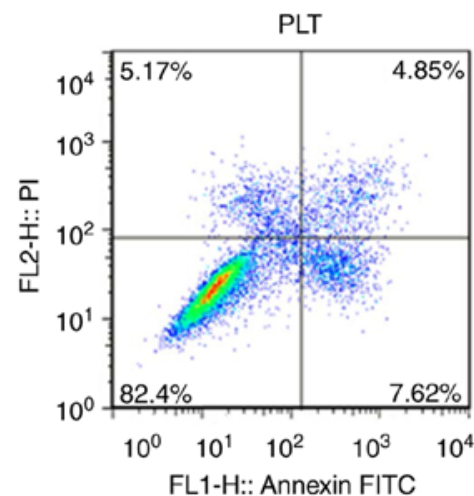

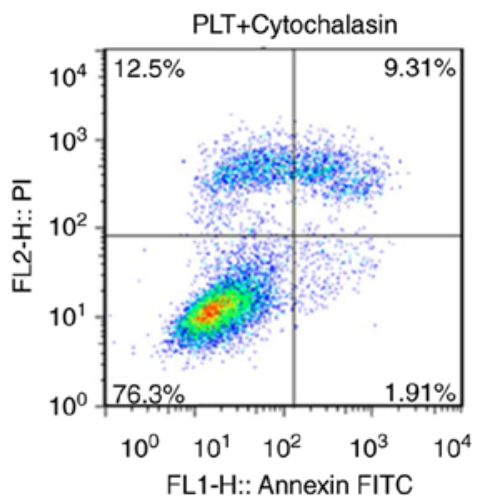

B
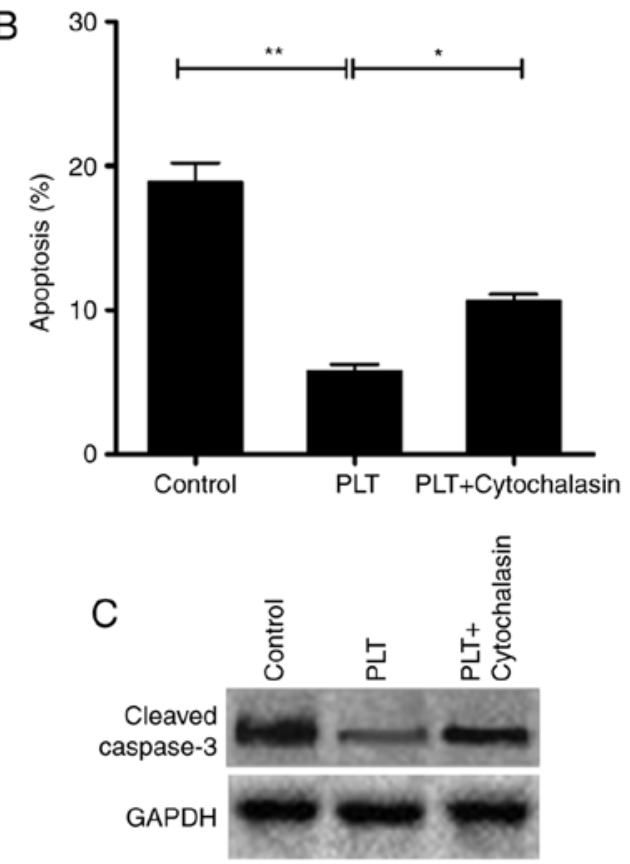

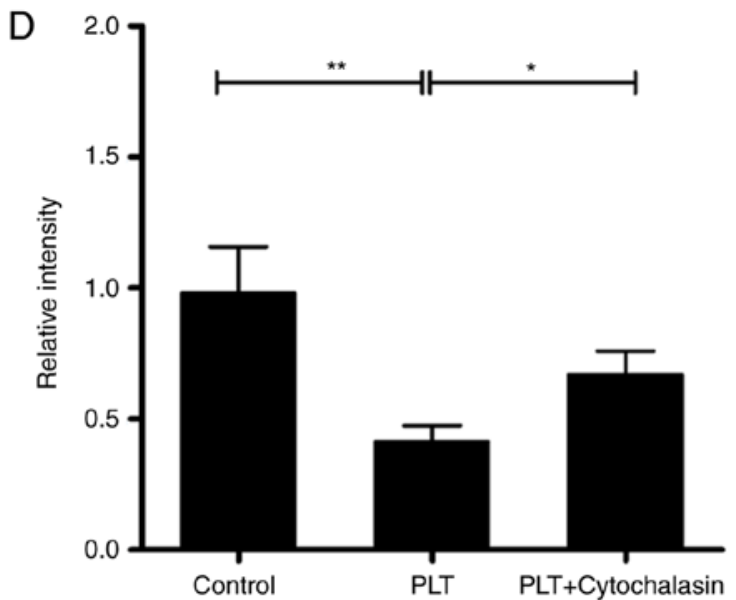

Figure 2. Phagocytosis of PLTs suppresses cell apoptosis. (A) Apoptosis of HBMECs was analyzed using flow cytometry with (B) relative intensity determined. (C) Expression levels of cleaved caspase-3 were examined using western blot analysis with (D) quantification. ${ }^{*} \mathrm{P}<0.05$ and ${ }^{* *} \mathrm{P}<0.01$. HBMECs, human brain microvascular endothelial cells; PLT, platelet.

with $0.1 \%$ Tris-buffered saline/Tween 20 at room temperature for $2 \mathrm{~h}$. The membrane was then incubated with anti-active caspase-3 antibody (1 $\mu \mathrm{g} / \mathrm{ml}$; cat. no. ab2302; Abcam), anti-AKT1/2/3 (phospho Y315+Y316+Y312) antibody (1:500; cat. no. ab131443), anti-pan-AKT antibody $(1 \mu \mathrm{g} / \mathrm{ml}$; cat. no. ab85683), anti-girdin antibody (1:40; cat. no. 18979; Takara Bio, Inc.), anti-girdin (phospho S1417) antibody (1:50; cat. no. 28067; Takara Bio, Inc.) or anti-GAPDH (6C5; 1:500; cat. no. ab8245; Abcam) overnight at $4^{\circ} \mathrm{C}$. The target bands were detected using a horseradish peroxidase-conjugated secondary antibody (1:2,000; cat. no. ab6721; Abcam) by incubation for $1 \mathrm{~h}$ at room temperature and then visualized using a BeyoECL plus enhanced chemiluminescence detection system (Beyotime Institute of Biotechnology). The band intensity was normalized to that of GAPDH and expressed as a relative ratio.

Statistical analysis. Statistical analysis was performed with SPSS 17.0 statistical software (SPSS, Inc., Chicago, IL, USA). For comparisons between groups, Student's t-test or one-way analysis of variance followed by Dunnet's multiple comparison test was used. $\mathrm{P}<0.05$ was considered to indicate a statistically significant difference.

\section{Results}

PLTs promotes resistance to cell senescence. The expression of SA- $\beta$-gal can be induced in senescent cells. As shown in Fig. $1 \mathrm{~A}$ and $\mathrm{B}$, the activity of SA- $\beta$-gal was reduced by PLT treatment. Cytochalasins can alter cell morphology by inhibiting actin polymerization. Following treatment with cytochalasin $\mathrm{D}$, the decline in activity was recovered partially. In addition, the cell viability was increased in the PLT group; and was decreased by cytochalasin D (Fig. 1C).

PLTs depress the apoptosis of HBMECs. The proliferation of cells can be inhibited by senescence or apoptosis. The apoptosis of HBMECs was determined in the present study. The results revealed that the level of apoptosis was decreased significantly in the PLT group, compared with that in the control group. By contrast, the number of apoptotic cells was higher in the cytochalasin D+PLT group, compared with that in the PLT group (Fig. 2A and B). In 
A
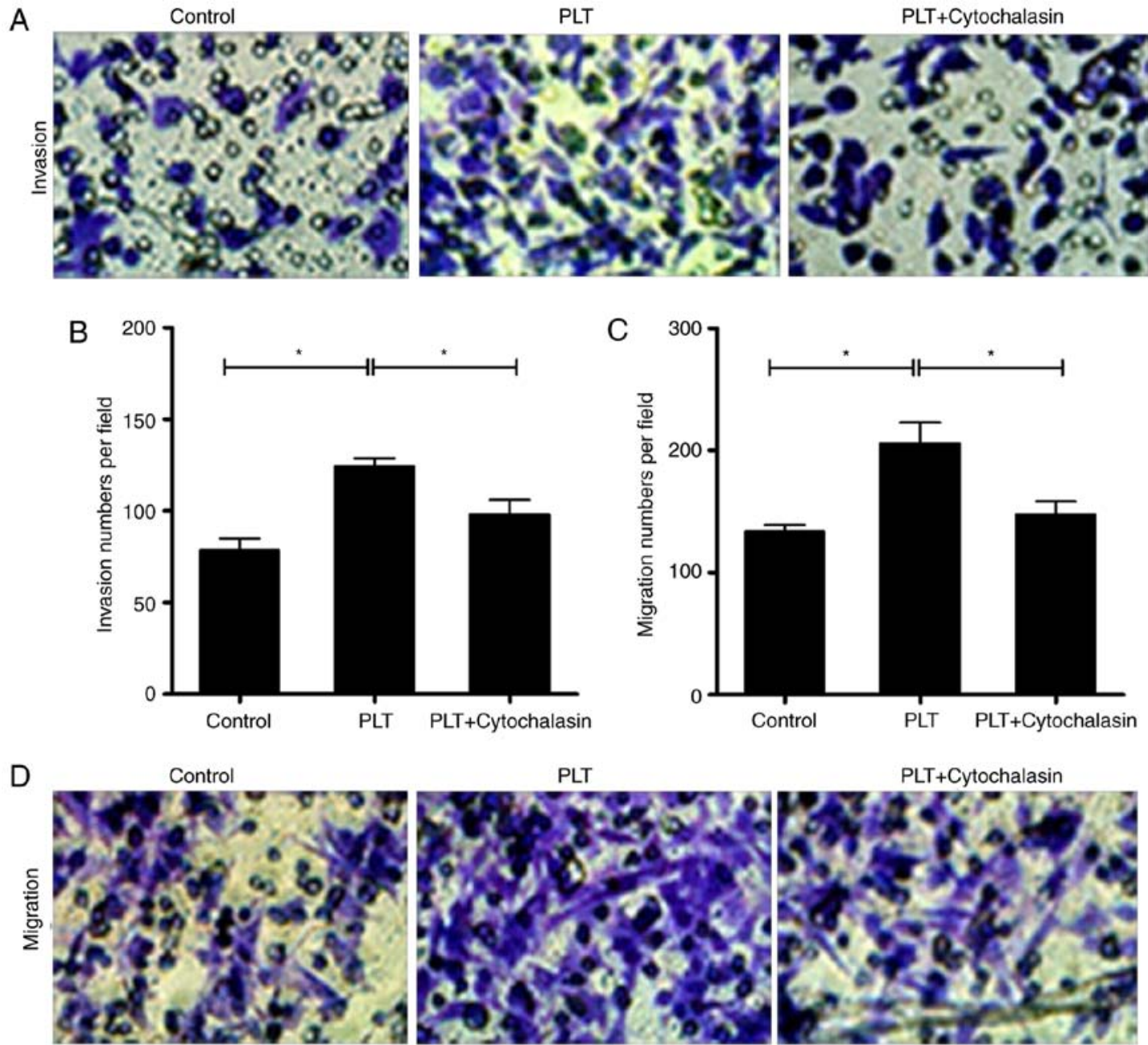

Figure 3. Phagocytosis of PLTs forces cell invasion and migration abilities. (A) Invasion ability of HBMECs was visualized and (B) measured using a Transwell assay. (C) Transwell assay for the migration of HBMECs, as shown in (D) images. Magnification x100. "P<0.05. HBMECs, human brain microvascular endothelial cells; PLT, platelet.

addition, the expression of cleaved caspase-3 was suppressed in the PLT group, compared with the control. Cytochalasin D recovered the protein level of cleaved caspase-3 (Fig. 2C and D).

PLTs enhance the invasion and migration capability of $H B M E C s$. Invasion and migration are the essential motilities of endothelial cells (30). The Transwell assays revealed that the invasion and migration abilities of the cells were increased by PLTs, whereas cytochalasin D repressed the cell invasion and migration induced by PLTs (Fig. 3A-D).

Effect of girdin on the engulfment of HBMECs to PLTs. The results from the transmission electron microscopy showed that, compared with the control group, knockdown of the expression of girdin inhibited the engraftment of endothelial cells to PLTs; and the mutated girdin at the 1417 locus also inhibited the engraftment of PLTs (Fig. 4A). In addition, the fluorescent intensity of PLT-labeling was reduced by the knockdown of girdin or the mutated girdin, compared with that in the PLT group (Fig. 4B and C). The downregulation of girdin was confirmed by western blot analysis (Fig. 4D). Furthermore, the engulfment of PLTs promoted the expression of girdin and p-girdin; whereas the expression of p-girdin was inhibited by the knockdown of girdin, while the expression of p-girdin did not appear to be influenced by m-girdin (Fig. 5A and B).

Girdin is co-located with PLTs in HBMECs. An immunofluorescence assay was performed to confirm the effect of girdin on the engulfment of PLTs. As shown in Fig. 6, girdin and p-girdin were located in the Golgi apparatus, and green fluorescence indicated phagocytic PLTs. Compared with the PLT group, the knockdown of girdin or the mutated girdin prevented the engulgment of PLTs.

Akt signals are involved in the engulfment of PLTs. It has been reported that girdin is a substrate of AKT/PKB, which is reported to be positively associated with phagocytosis (31). Triciribine, a specific inhibitor of AKT phosphorylation (32), was used in the present study to further determine the involvement of AKT. The inhibition of senescence of HBMECs caused by PLTs was reversed by triciribine (Fig. 7A). In addition, the cell invasion and migration capabilities were decreased by triciribine, compared with those in the PLT group (Fig. 7B-D). Mechanically, p-AKT was increased in PLT group, whereas treatment with triciribine significantly inhibited the activity 

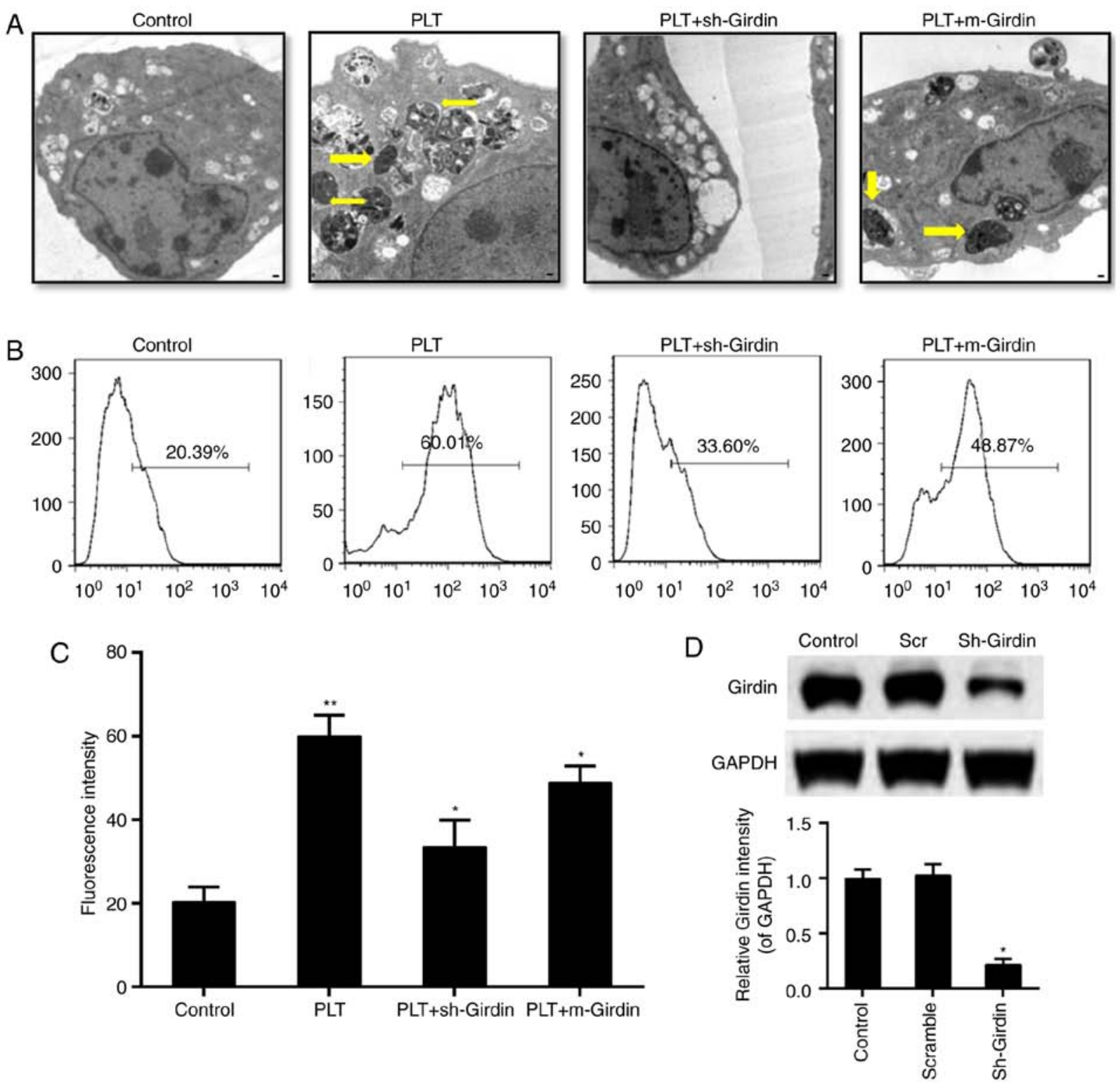

Figure 4. Girdin is essential for the engulfment of PLTs. (A) Engulfment in HBMECs of PLTs was observed under a transmission electron microscope. Scale bar $=5 \mu \mathrm{m}$. (B) Flow cytometric analysis of the engulfment of PLTs with (C) quantification. (D) Transfection efficiency of the sh-girdin vector was detected using western blot analysis. ${ }^{*} \mathrm{P}<0.05$ and ${ }^{* *} \mathrm{P}<0.01$. PLT, platelet; HBMECs, human brain microvascular endothelial cells; sh, short hairpin RNA; m, mutated.

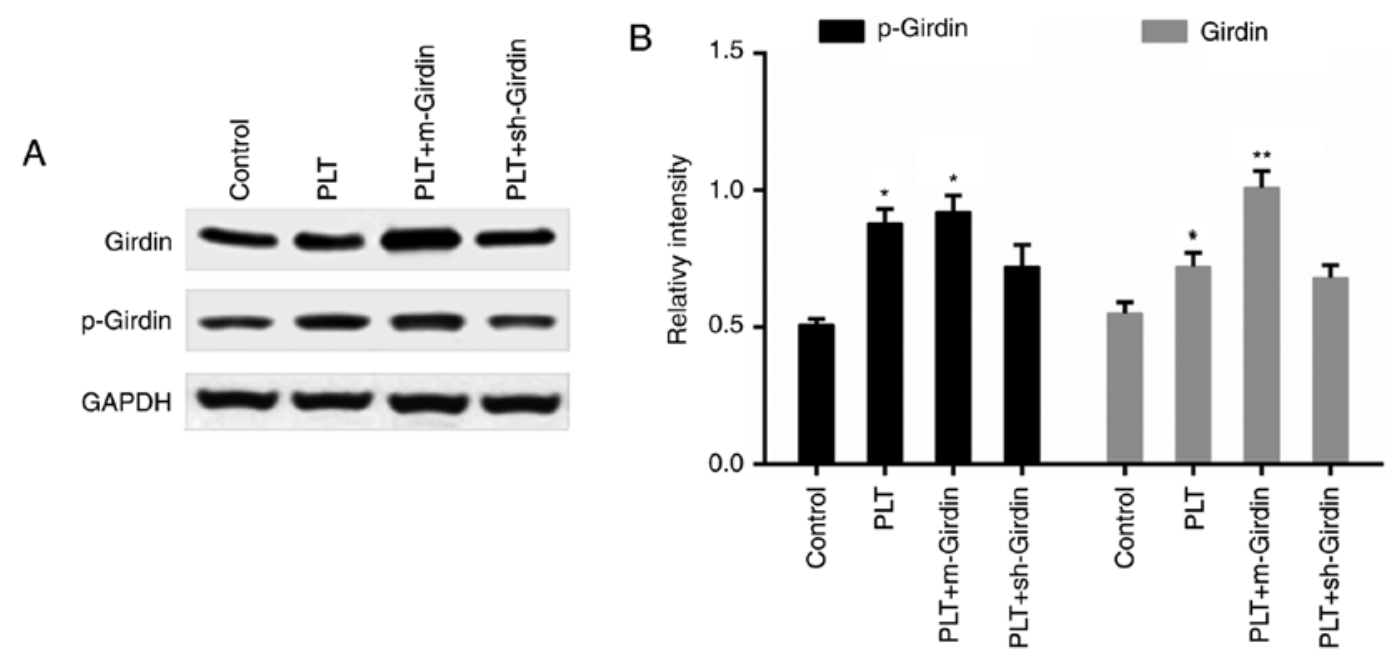

Figure 5. Expression of girdin and p-girdin are increased by PLTs. (A) Images and (B) relative intensity of western blot analysis to examine the expression of girdin and p-girdin. ${ }^{*} \mathrm{P}<0.05$ and ${ }^{* *} \mathrm{P}<0.01$. PLT, platelet; $\mathrm{p}$-, phosphorylated; sh, short hairpin RNA; m, mutated. 

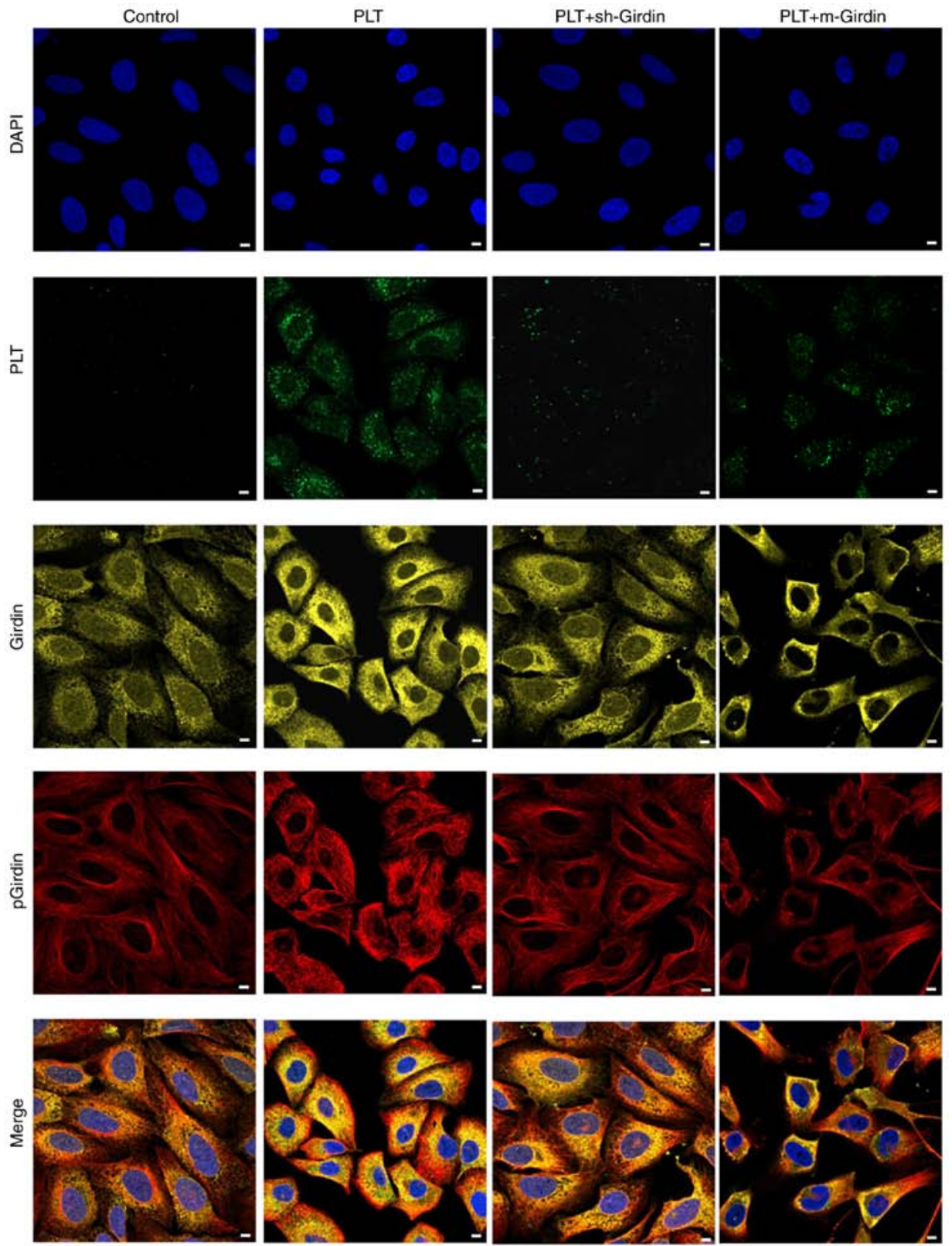

Figure 6. PLTs, girdin and p-girdin are co-localized in HBMECs. Confocal microscopy was used to observe the localization of PLTs, girdin and p-girdin. Scale bar=5 $\mu \mathrm{m}$. PLT, platelet; p-, phosphorylated; HBMECs, human brain microvascular endothelial cells; sh, short hairpin RNA; m, mutated.

of AKT (Fig. 8A and B). This indicated that the activation of AKT signals was involved in the engulfment of PLTs.

\section{Discussion}

BBB is a well-differentiated microvessel network in the CNS and important to the hemostasis of brain tissues. Brain angiogenesis is a critical step in the development of the BBB, which is dependent on the invasion of endothelial cells into the avascular neuroectoderm and formation of intraneural vessels $(33,34)$. It is promising for the protection of endothelial cells from injury and aging. In the present study, co-cultures of HAs and HBMECs in vitro were used to mimic the BBB in living cells. It was shown that PLTs promoted the resistance to senescence of HBMECs, whereas this effect was mitigated by treatment with cytochalasin D. Although the effect of extracellular PLTs cannot completely excluded, it was suggested that the survival of HBMECa was partly promoted by the phagocytosis of PLTs. The apoptosis of HBMECs was further examined, and the results revealed that the level of apoptosis was significantly decreased by PLTs. In addition, the expression of cleaved caspase-3, an apoptosis-associated protein (35), was inhibited by PLTs. These results indicated that treatment with PLTs increased proliferation and depressed endothelial apoptosis. This was consistent with previous reports that PLTs enhance the growth and integrity of endothelial cells $(36,37)$. The invasion and migration of endothelial cells is an important event in angiogenesis (38). To further confirm the effect of PLTs, a Transwell assay was performed. It was shown that the PLTs augmented the invasion and migration abilities of the endothelial cells. Taken together, treatment with PLTs was beneficial for the healthy situation of endothelial cells. Consistently, 
A
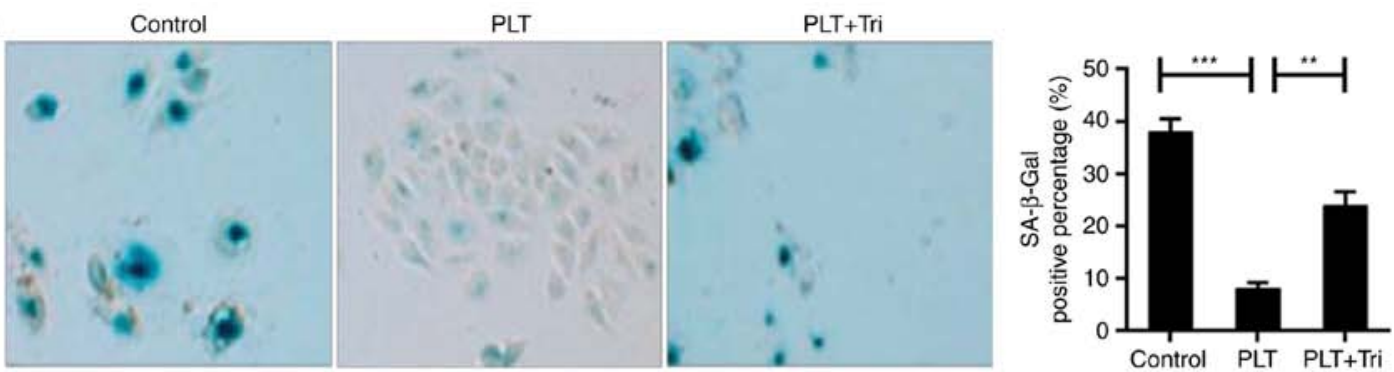

B
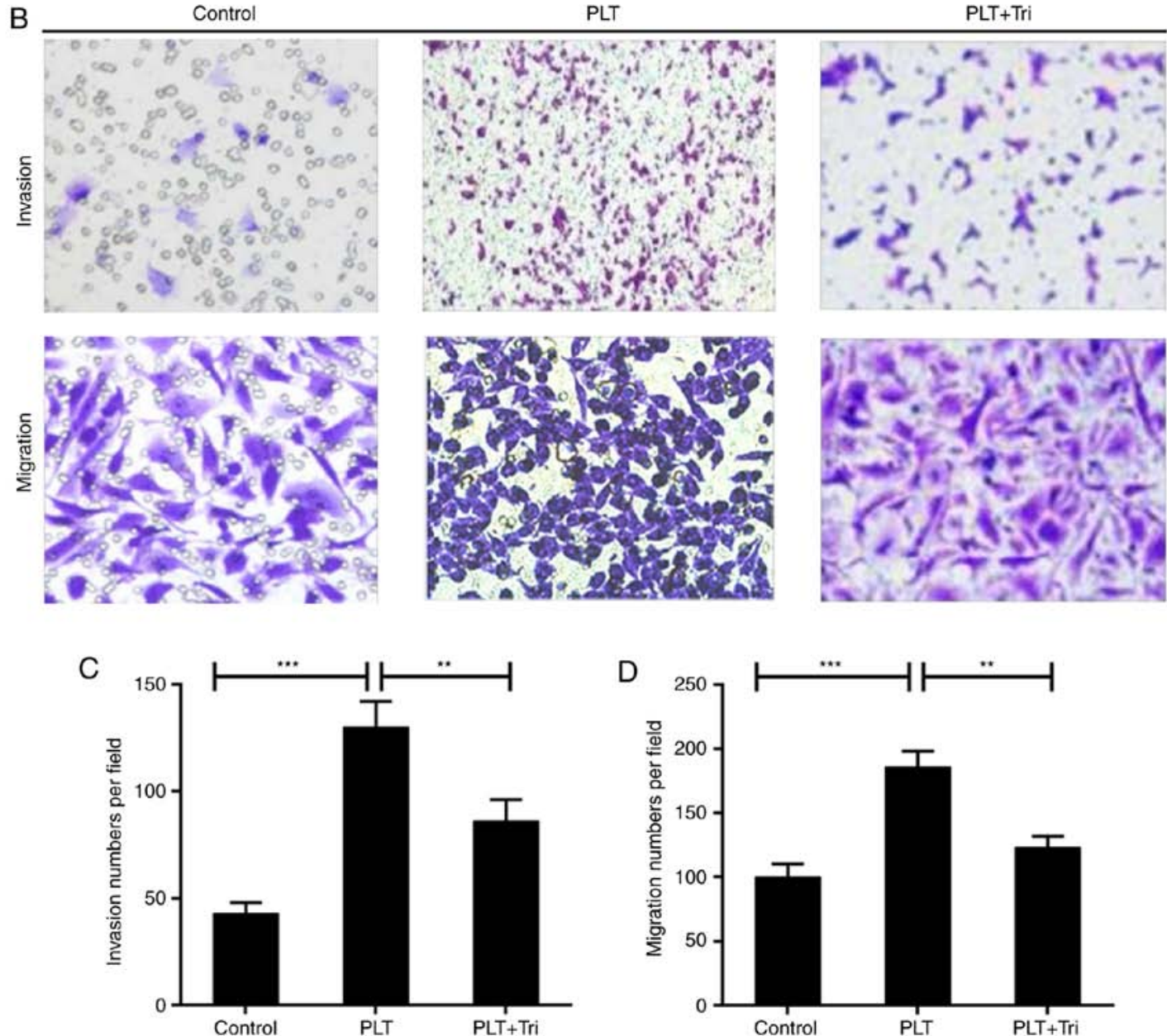

Figure 7. Activation of AKT facilitates the effect of PLTs on HBMECs. (A) Inhibition of AKT increased the activity of $\beta$-gal (magnification $x 400$ ). (B) Inhibition of AKT depressed the (C) invasion and (D) migration of HBMECs (magnification, $\mathrm{x} 100)$ ) ${ }^{* *} \mathrm{P}<0.01$ and ${ }^{* * * *} \mathrm{P}<0.001$. PLT, platelet; HBMECs, human brain microvascular endothelial cells; SA- $\beta$-gal, senescence-associated $\beta$-galactosidase; Tri, triciribine.

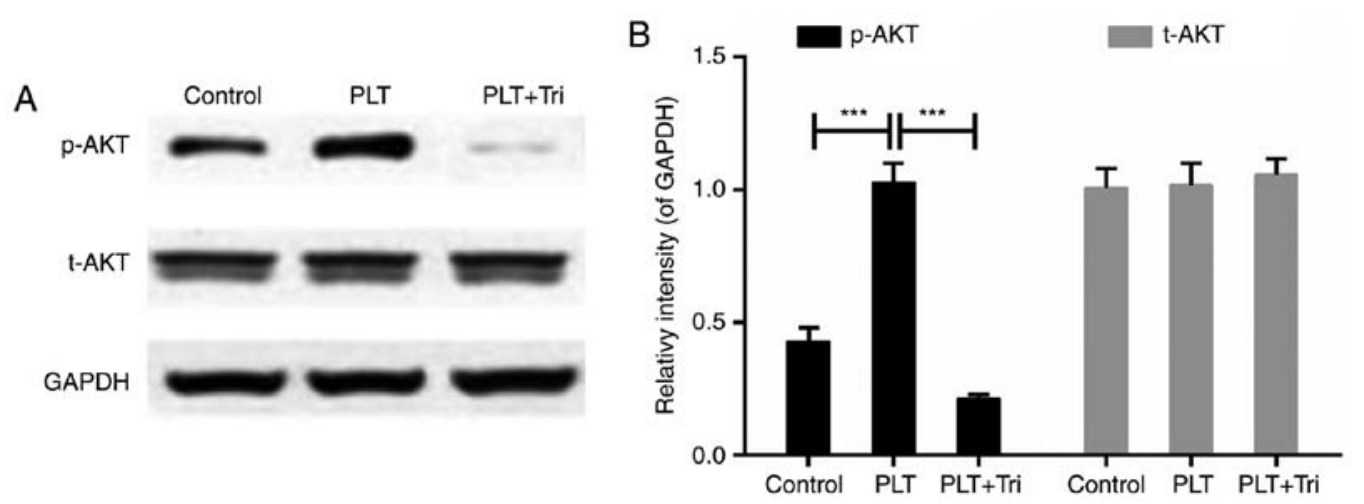

Figure 8. Activity of AKT is increased by PLTs. Expression levels of AKT and p-AKT were (A) visualized and (B) measured using western blot analysis. **** $\mathrm{P}<0.001$. PLT, platelet; Tri, triciribine; $\mathrm{p}-$, phosphorylated; $\mathrm{t}-$, total. 
several studies have confirmed that PRP exerts protective effect via anti-inflammatory and anti-apoptotic effects, and by promoting angiogenesis $(20,39)$. However, platelet aggregation and abnormal angiogenesis are considered to be harmful to human health (40-42). The concentration used in the present study may be not the optimal concentration for delaying cell aging, and further investigations are warranted for its potential clinical use. It is important to regulate the phagocytosis of PLTs in an appropriate manner.

PLTs can be engulfed by endothelial cells $(24,29)$. The phagocytosis of PLTs was observed under a transmission electron microscopic. It was shown that the PLTs were engulfed by HBMECs. Girdin, as an actin-binding AKT substrate, is able to regulate angiogenesis (12). Girdin is also important for the migration of endothelial cells during postnatal angiogenesis $(11,12)$. Therefore, it is possible that girdin may be associated with the protective effect of PLTs on endothelial cells. As expected, the depletion of girdin and mutated girdin (resistant to phosphorylation at 1417) suppressed the phagocytosis of PLTs by HBMECs. In addition, the expression of girdin and p-girdin were induced by PLTs. The co-localization of PLTs, girdin and p-girdin further demonstrated the potential role of girdin in the positive effect of PLTs on endothelial cells. As the reduction of girdin and p-girdin reduced the phagocytosis of PLTs, the depletion of girdin may have a negative feedback effect on the phagocytosis in endothelial cells of PLTs.

In consideration of the regulatory association between girdin and AKT, the involvement of AKT signals in the present study model was investigated using its specific inhibitor. The results confirmed that the repression of AKT signals reversed the effect of PLTs through the aggravation of senescence and the inhibition of invasion and migration of HBMECs. It was shown that phagocytosis of the PLTs induced the activation of AKT signals and thus contributed to cell growth and survival. This result was in line with previous reports $(36,43)$. In addition, girdin can be phosphorylated by AKT at serine 1417. Therefore, the phosphorylation of girdin mediated by AKT may be the mechanism by which phagocytosis of PLTs promoted the survival of endothelial cells. This result was compatible with a previous study that highlighted the major effect of girdin and its Akt-mediated phosphorylation on migration and proliferation following vascular injury (19). Girdin is also associated with Wnt signaling pathways (44), indicating the versatile function of girdin in different signaling pathways. The intracellular signaling pathways are complex and there may be cross-talk, therefore, it is possible that other signals or pathways are involved in the phagocytosis of PLTs. For example, forkhead box 3a (Fox3a), another downstream target of the AKT signal, has been shown to be essential in angiogenesis (45); additionally, the extracellular signal-regulated kinase (ERK) pathway is another important signaling pathway for cell survival, angiogenesis and phagocytosis (46-48). Although the role of other signals, including the Fox3a and ERK pathways, were not elucidated in the present study, they may be modulated following the phagocytosis of PLTs and may be potential targets of novel therapeutics for delaying the aging of endothelial cells.

In conclusion, it was shown that the engulfment of PLTs delayed endothelial cell aging via the promotion of cell proliferation and inhibition of apoptosis, and the enhancement of cell invasion and migration abilities. Girdin was essential for the phagocytosis of PLTs, in which AKT may be involved in the phosphorylation of girdin. The results of the present study indicated the significance of understanding the effect of PLTs on endothelial cells, which may assist in developing novel therapeutics for CNS diseases associated with the aging of endothelial cells.

\section{Acknowledgements}

Not applicable.

\section{Funding}

This study was supported by the Natural Science Foundation of China (grant no. 31371160).

\section{Availability of data and materials}

All data generated or analyzed during this study are included in this published article.

\section{Authors' contributions}

YLa, YoLi and DL wrote the manuscript. YLa, YoLi, DL, PL, JW, YD and GY performed the experiments. YLa and YaLi designed the study. YLa, YoLi, DL, PL and JW performed the data analysis. YLa, YoLi, and DL revised the manuscript and all authors reviewed the manuscript.

\section{Ethics approval and consent to participate}

The present study was approved by the Ethics Committee of Beijing Hospital (Beijing, China). Informed consent was obtained from the volunteers.

\section{Consent for publication}

Informed consent was obtained from all participants for the publication of their data.

\section{Competing interests}

The authors declare that they have no competing interests.

\section{References}

1. Yang Y and Rosenberg GA: Blood-brain barrier breakdown in acute and chronic cerebrovascular disease. Stroke 42: 3323-3328, 2011.

2. Lee SW, Kim WJ, Choi YK, Song HS, Son MJ, Gelman IH, Kim YJ and Kim KW: SSeCKS regulates angiogenesis and tight junction formation in blood-brain barrier. Nat Med 9: 900-906, 2003.

3. Lahteenvuo J and Rosenzweig A: Effects of aging on angiogenesis. Circ Res 110: 1252-1264, 2012.

4. Capettini LS, Cortes SF, Silva JF, Alvarez-Leite JI and Lemos VS: Decreased production of neuronal NOS-derived hydrogen peroxide contributes to endothelial dysfunction in atherosclerosis. Br J Pharmacol 164: 1738-1748, 2011.

5. Pelham CJ, Keen HL, Lentz SR and Sigmund CD: Dominant negative PPARgamma promotes atherosclerosis, vascular dysfunction, and hypertension through distinct effects in endothelium and vascular muscle. Am J Physiol Regul Integr Comp Physiol 304: R690-R701, 2013.

6. Erusalimsky JD and Skene C: Mechanisms of endothelial senescence. Exp Physiol 94: 299-304, 2009. 
7. Rivard A, Fabre JE, Silver M, Chen D, Murohara T, Kearney M, Magner M, Asahara T and Isner JM: Age-dependent impairment of angiogenesis. Circulation 99: 111-120, 1999.

8. Fujio $\mathrm{Y}$ and Walsh K: Akt mediates cytoprotection of endothelial cells by vascular endothelial growth factor in an anchorage-dependent manner. J Biol Chem 274: 16349-16354, 1999.

9. Shiojima I and Walsh K: Role of Akt signaling in vascular homeostasis and angiogenesis. Circ Res 90: 1243-1250, 2002.

10. Sata M, Maejima Y, Adachi F, Fukino K, Saiura A, Sugiura S Aoyagi T, Imai Y, Kurihara H, Kimura K, et al: A mouse model of vascular injury that induces rapid onset of medial cell apoptosis followed by reproducible neointimal hyperplasia. J Mol Cell Cardiol 32: 2097-2104, 2000.

11. Enomoto A, Murakami H, Asai N, Morone N, Watanabe T, Kawai K, Murakumo Y, Usukura J, Kaibuchi K and Takahashi M Akt/PKB regulates actin organization and cell motility via Girdin/APE. Dev Cell 9: 389-402, 2005.

12. Kitamura T, Asai N, Enomoto A, Maeda K, Kato T, Ishida M, Jiang P, Watanabe T, Usukura J, Kondo T, et al: Regulation of VEGF-mediated angiogenesis by the Akt/PKB substrate Girdin. Nat Cell Biol 10: 329-337, 2008.

13. Angiolillo DJ, Ferreiro JL, Price MJ, Kirtane AJ and Stone GW: Platelet function and genetic testing. J Am Coll Cardiol 62 (Suppl 17): S21-S31, 2013.

14. de Groot PG, Urbanus RT and Roest M: Platelet interaction with the vessel wall. Handb Exp Pharmacol 210: 87-110, 2012.

15. Sopova K, Tatsidou P and Stellos K: Platelets and platelet interaction with progenitor cells in vascular homeostasis and inflammation. Curr Vasc Pharmacol 10: 555-562, 2012.

16. Sharma D, Brummel-Ziedins KE, Bouchard BA and Holmes CE: Platelets in tumor progression: A host factor that offers multiple potential targets in the treatment of cancer. J Cell Physiol 229: $1005-1015,2014$

17. Radziwon-Balicka A, Moncada de la Rosa C and Jurasz P: Platelet-associated angiogenesis regulating factors: A pharmacological perspective. Can J Physiol Pharmacol 90: 679-688, 2012.

18. Andrae J, Gallini R and Betsholtz C: Role of platelet-derived growth factors in physiology and medicine. Genes Dev 22: 1276-1312, 2008.

19. Dohan Ehrenfest DM, Andia I, Zumstein MA, Zhang CQ, Pinto NR and Bielecki T: Classification of platelet concentrates (Platelet-Rich Plasma-PRP, Platelet-Rich Fibrin-PRF) for topical and infiltrative use in orthopedic and sports medicine: Current consensus, clinical implications and perspectives. Muscles Ligaments Tendons J 4: 3-9, 2014.

20. Kakudo N, Morimoto N, Kushida S, Ogawa T and Kusumoto K: Platelet-rich plasma releasate promotes angiogenesis in vitro and in vivo. Med Mol Morphol 47: 83-89, 2014.

21. Marx RE: Platelet-rich plasma: Evidence to support its use. J Oral Maxillofac Surg 62: 489-496, 2004.

22. Hayon Y, Dashevsky O, Shai E, Brill A, Varon D and Leker RR Platelet microparticles induce angiogenesis and neurogenesis after cerebral ischemia. Curr Neurovasc Res 9: 185-192, 2012.

23. Ohtsuka M, Sasaki K, Ueno T, Seki R, Nakayoshi T, Koiwaya H, Toyama Y, Yokoyama S, Mitsutake Y, Chibana H, et al: Platelet-derived microparticles augment the adhesion and neovascularization capacities of circulating angiogenic cells obtained from atherosclerotic patients. Atherosclerosis 227: 275-282, 2013

24. Kuckleburg CJ, McClenahan DJ and Czuprynski CJ: Platelet activation by histophilus somni and its lipooligosaccharide induces endothelial cell proinflammatory responses and platelet internalization. Shock 29: 189-196, 2008.

25. Deli MA, Abraham CS, Kataoka Y and Niwa M: Permeability studies on in vitro blood-brain barrier models: Physiology, pathology, and pharmacology. Cell Mol Neurobiol 25: 59-127, 2005 .

26. Bachmeier C, Mullan $\mathrm{M}$ and Paris D: Characterization and use of human brain microvascular endothelial cells to examine $\beta$-amyloid exchange in the blood-brain barrier. Cytotechnology 62: 519-529, 2010.

27. Helms HC, Abbott NJ, Burek M, Cecchelli R, Couraud PO, Deli MA, Förster C, Galla HJ, Romero IA, Shusta EV, et al: In vitro models of the blood-brain barrier: An overview of commonly used brain endothelial cell culture models and guidelines for their use. J Cereb Blood Flow Metab 36: 862-890, 2016.
28. Gloesenkamp CR, Nitzsche B, Ocker M, Di Fazio P, Quint K, Hoffmann B, Scherubl H and Hopfner M: AKT inhibition by triciribine alone or as combination therapy for growth control of gastroenteropancreatic neuroendocrine tumors. Int J Oncol 40: 876-888, 2012 .

29. Jiang P, Ren YL,Lan Y,Li JL, Luo J, Li J and Cai JP: Phagocytosis of platelets enhances endothelial cell survival under serum deprivation. Exp Biol Med (Maywood) 240: 876-883, 2015.

30. van Moorselaar RJ and Voest EE: Angiogenesis in prostate cancer: Its role in disease progression and possible therapeutic approaches. Mol Cell Endocrinol 197: 239-250, 2002.

31. Luster AD, Alon R and von Andrian UH: Immune cell migration in inflammation: Present and future therapeutic targets. Nat Immunol 6: 1182-1190, 2005

32. Garrett CR, Coppola D, Wenham RM, Cubitt CL, Neuger AM, Frost TJ, Lush RM, Sullivan DM, Cheng JQ and Sebti SM: Phase I pharmacokinetic and pharmacodynamic study of triciribine phosphate monohydrate, a small-molecule inhibitor of AKT phosphorylation, in adult subjects with solid tumors containing activated AKT. Invest New Drugs 29: 1381-1389, 2011.

33. Risau W and Wolburg H: Development of the blood-brain barrier. Trends Neurosci 13: 174-178, 1990.

34. Plate KH: Mechanisms of angiogenesis in the brain. J Neuropathol Exp Neurol 58: 313-320, 1999.

35. Porter AG and Janicke RU: Emerging roles of caspase-3 in apoptosis. Cell Death Differ 6: 99-104, 1999.

36. Johnson SA, Balboa RS, Dessel BH, Monto RW, Siegesmund KA and Greenwalt TJ: The mechanism of the endothelial supporting function of intact platelets. Exp Mol Pathol 3: 115-127, 1964.

37. Lang D, Dohle F, Terstesse M, Bangen P, August C, Pauels HG and Heidenreich S: Down-regulation of monocyte apoptosis by phagocytosis of platelets: Involvement of a caspase-9, caspase-3, and heat shock protein 70-dependent pathway. J Immunol 168: 6152-6158, 2002.

38. Shin WS, Maeng YS, Jung JW, Min JK, Kwon YG and Lee ST: Soluble PTK7 inhibits tube formation, migration, and invasion of endothelial cells and angiogenesis. Biochem Biophys Res Commun 371: 793-798, 2008

39. Moussa M, Lajeunesse D, Hilal G, El Atat O, Haykal G, Serhal R, Chalhoub A, Khalil C and Alaaeddine N: Platelet rich plasma (PRP) induces chondroprotection via increasing autophagy, anti-inflammatory markers, and decreasing apoptosis in human osteoarthritic cartilage. Exp Cell Res 352: 146-156, 2017.

40. Luzak B, Golanski J, Rozalski M, Krajewska U, Olas B and Watala C: Extract from Aronia melanocarpa fruits potentiates the inhibition of platelet aggregation in the presence of endothelial cells. Arch Med Sci 6: 141-144, 2010.

41. Metzig C, Grabowska E, Eckert K, Rehse K and Maurer HR: Bromelain proteases reduce human platelet aggregation in vitro, adhesion to bovine endothelial cells and thrombus formation in rat vessels in vivo. In Vivo 13: 7-12, 1999.

42. Wen H, Lu Y, Yao H and Buch S: Morphine induces expression of platelet-derived growth factor in human brain microvascular endothelial cells: Implication for vascular permeability. PLoS One 6: e21707, 2011.

43. Rauch BH, Millette E, Kenagy RD, Daum G, Fischer JW and Clowes AW: Syndecan-4 is required for thrombin-induced migration and proliferation in human vascular smooth muscle cells. J Biol Chem 280: 17507-17511, 2005.

44. Enomoto A, Ping J and Takahashi M: Girdin, a novel actin-binding protein, and its family of proteins possess versatile functions in the Akt and Wnt signaling pathways. Ann N Y Acad Sci 1086: 169-184, 2006

45. Skurk C, Maatz H, Kim HS, Yang J, Abid MR, Aird WC and Walsh K: The Akt-regulated forkhead transcription factor FOXO3a controls endothelial cell viability through modulation of the caspase-8 inhibitor FLIP. J Biol Chem 279: 1513-1525, 2004.

46. Yang JY, Michod D, Walicki J and Widmann C: Surviving the kiss of death. Biochem Pharmacol 68: 1027-1031, 2004.

47. Curry JM, Eubank TD, Roberts RD, Wang Y, Pore N, Maity A and Marsh CB: M-CSF signals through the MAPK/ERK pathway via $\mathrm{Sp} 1$ to induce VEGF production and induces angiogenesis in vivo. PLoS One 3: e3405, 2008.

48. Jehle AW, Gardai SJ, Li S, Linsel-Nitschke P, Morimoto K, Janssen WJ, Vandivier RW, Wang N, Greenberg S Dale BM, et al: ATP-binding cassette transporter A7 enhances phagocytosis of apoptotic cells and associated ERK signaling in macrophages. J Cell Biol 174: 547-556, 2006. 